\title{
Evaluation of Post Treatment Satisfaction in Orthodontic Patients
}

\author{
Sanket Platia', Mukesh Kumar², Aditi Khanna ${ }^{3}$, Sommya Kumari ${ }^{4}$ \\ ${ }^{1}$ Associate Professor, Department of Dentistry, Maharishi Markandeshwar Medical College and Hospital, Kumarhatti, Solan, H.P, ${ }^{2}$ Assistant Professor and HOD, \\ Faculty of Dentistry, Vardhman Institute of Medical Sciences, Pawapuri, Nalanda, Bihar, ${ }^{3}$ Private practice, ${ }^{4}$ Post Graduate Student, Vardhman Institute of Medical \\ Sciences, Pawapuri, Nalanda, Bihar.
}

\section{Abstract}

Background: The goal of orthodontic treatment is to produce a normal or ideal occlusion. However, there is a large variation in treatment outcome. There are a number of factors that may influence patient satisfaction; this includes physical comfort, emotional support, patient expectations and respect for their preference. The aim of the study was to assess the level of satisfaction of orthodontic patients after the treatment. Subjects and Methods: This study design involved a cross-sectional study of 170 orthodontic patients in the final stage of their orthodontic treatment. Results: Study show that a higher percentage of the participants reported that self-motivation was the main reason to go and see the orthodontist. A significantly high percentage of female patients reported that aesthetics was the main reason for seeking orthodontic treatment with more than half of the participants saying that they were very satisfied. Furthermore, 58\% of the participants reported that orthodontic treatment improved their confidence and communication skills with no complications during the treatment. Conclusion: The overall response to the questionnaire revealed that, in general, patients who undergone orthodontic treatment remained satisfied with their facial aesthetics in a long-term period after the treatment was done.

Keywords: Orthodontics, Aesthetics, Patient satisfaction.

Corresponding Author: Dr. Mukesh Kumar, Assistant Professor and HOD, Faculty of Dentistry, Vardhman Institute of Medical Sciences, Pawapuri, Nalanda, Bihar.

Received: January 2019

Accepted: February 2019

\section{Introduction}

An important motivational factor for orthodontic treatment is improved dental facial appearance. ${ }^{[1]}$ The relationship between physical appearance and perception of an aesthetic deviation, and the impact of such a deviation on self-esteem and body image are important issues in determining the benefits gained from orthodontic treatment. ${ }^{[2]}$

Furthermore, a variety of social, cultural, psychological factors, and personal norms influence perception of physical attractiveness. ${ }^{[3]}$ Studies in social psychology indicate that physical attractiveness plays a major role in social interaction and influences the impression of an individual's social skill. ${ }^{[4]}$

As orthodontic treatment improves facial appearance, it is assumed to increase self-worth. However, this hypothesis is difficult to verify. Studies on self-concept perception during orthodontic treatment versus long-lasting effect on selfesteem revealed inconclusive result. ${ }^{[1,5]}$ The major reason behind opting for orthodontic treatment is to improve the facial form and aesthetics. ${ }^{[1,2]}$ The major challenge in the field of Orthodontics is that the clinician is expected to correct the facial form as a result of improper dental occlusion as well as the skeletal pattern.

Post treatment retention remained to be a challenge to the orthodontic profession. Usually, the goal of orthodontic treatment is to produce a ideal occlusion that is morphologically stable and aesthetically and functionally well-adjusted. There is, however, a large variation in treatment outcome because of the severity and type of malocclusion, treatment approach, patient cooperation, and growth and adaptability of the hard and soft tissues. ${ }^{[6]}$ Quality assessment of health care is in the hands of the patient, clinician or the parents. Parental feedback regarding the treatment may be clouded by past experience. So, The Clinician should take in to account the Parent as well as the child's feedback and judiciously use it. ${ }^{[7]}$ The satisfaction of patients relies on the physical basis, emotional basis and in satisfying their own expectations regarding their appearance. ${ }^{[8-10]}$ Relying only on Clinician's judgement may not be reliable and valid in all cases. ${ }^{[1]}$ It is now evident that patient satisfactory measures should include criteria that are important to the patient to have a positive feeling about their appearance. ${ }^{[12]}$

Therefore, the aim of the study is to assess the level of satisfaction of orthodontic patients after the completion of the treatment.

\section{Subjects and Methods}

The research design was a cross-sectional study involving 170 orthodontic patients at the Patna Dental Clinic, Ashok Raj Path, Patna, Bihar and, Gums and Braces Multispeciality Dental Clinic, Rajgarh Road, Solan, H.P. 
during January 2017 to December 2017. Informed consent was taken from the patients and their parents. The samples were asked to complete the questionnaire in the waiting area. Patients selected to answer only if they are in the final stage of the treatment.

\section{$\underline{\text { Statistical Analysis }}$}

Statistical analysis was done in SPSS program version 10 in which frequency measurement and Chi-Square Test were used.

\section{Results}

This study included 170 subjects (74 males and 96 females) in the final stage of their orthodontic treatment [Figure 1].

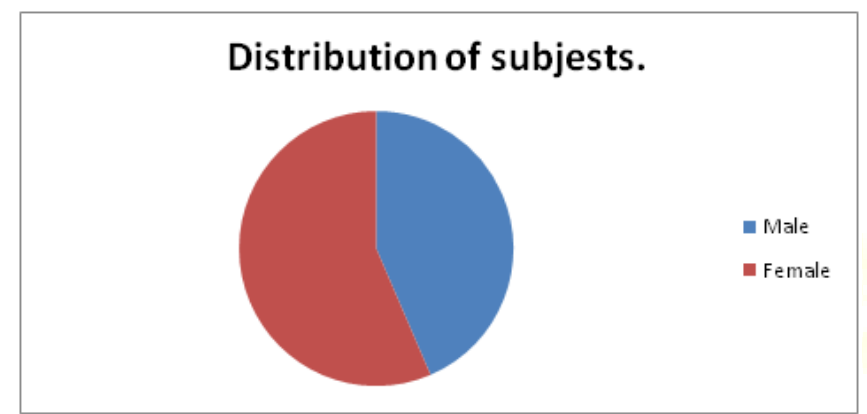

\section{Figure 1:}

The present study showed $69 \%$ of the patients were selfmotivated that encouraged them to start an orthodontic treatment, with no statistical difference between the responses of male and female patients. [Figure 2]

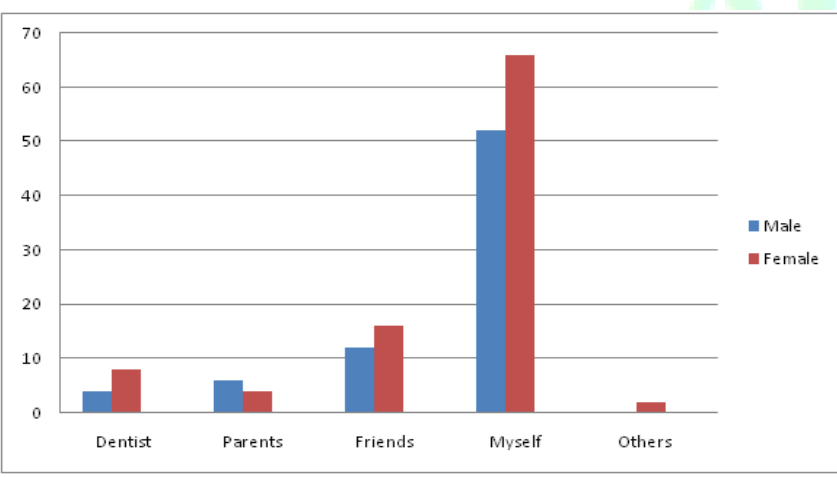

Figure 2: Who Encouraged you to start the orthodontic treatment?

The study also revealed that, wish to look aesthetically appealing remained the choice for $95 \%$ patients. Function and speech remained the area of non interest. [Figure 3]

Post treatment satisfaction level was examined at three points. $91 \%$ patients showed their satisfaction in overall treatment [Figure 4]. $86 \%$ patients were satisfied with their post treatment facial improvement, while only $7 \%$ felt that the outlook of their face was not compatible with their teeth [Figure 5]. Considering the smile improvement, $88 \%$ noticed a improvement and felt a significant difference with the way they smile while 5\% were non satisfied. [Figure 6]

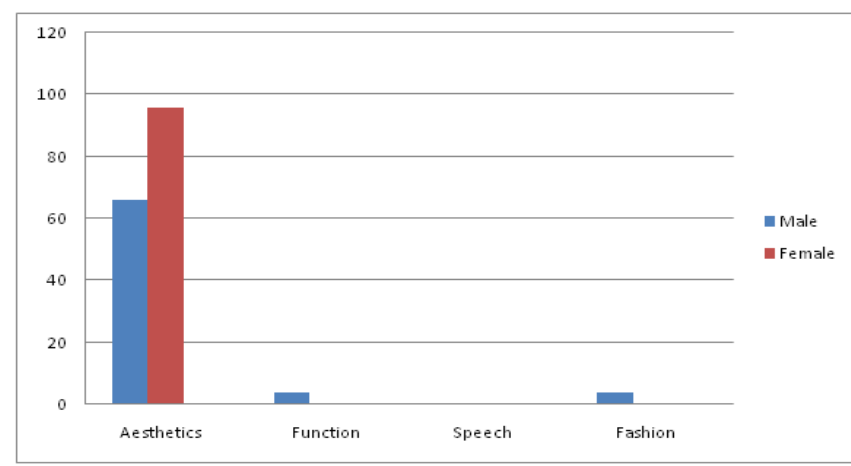

Figure 3: Mainly reported reason to do orthodontic treatment?

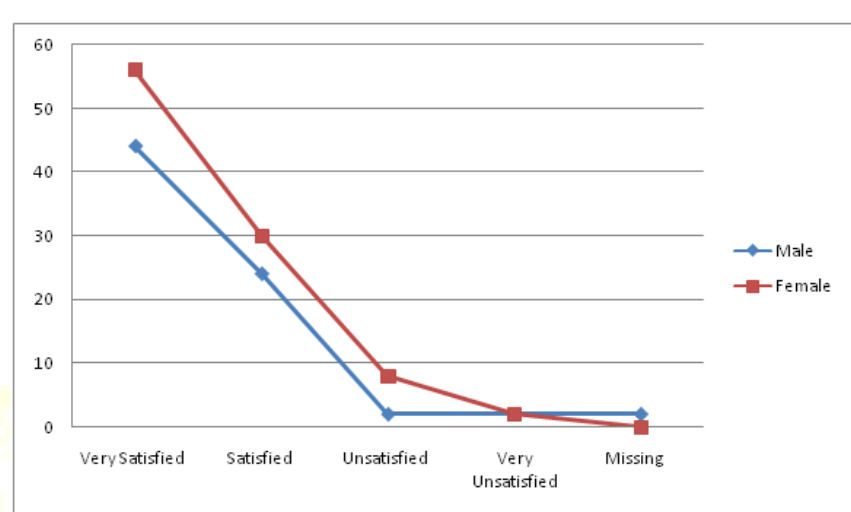

Figure 4: Level of satisfaction in regard to overall treatment ?

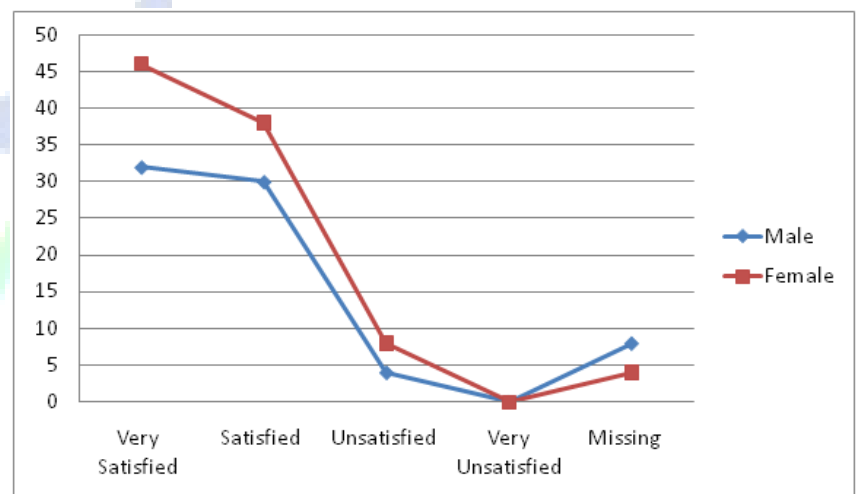

Figure 5: Level of satisfaction in regard to overall facial appearance after treatment?

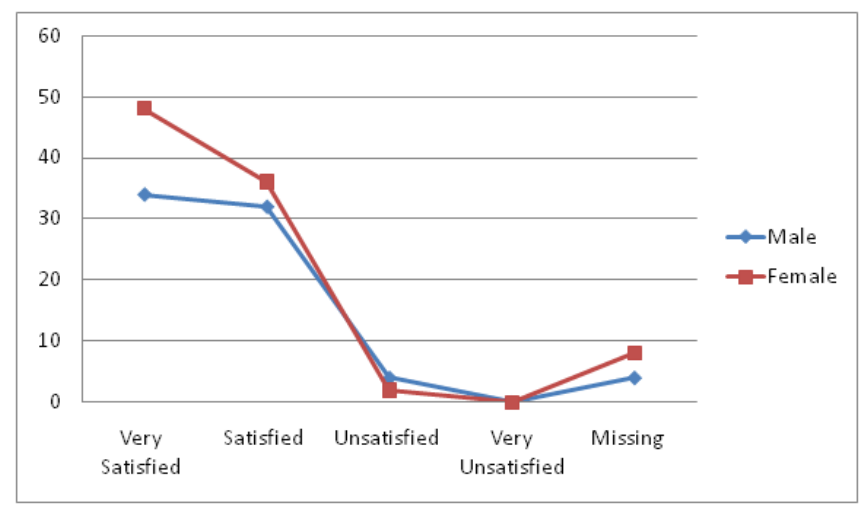

Figure 6: Level of satisfaction in regard to smile after the treatment.?

A majority of the participants (58\%) reported a positive answer stating that orthodontic treatment improved their 
confidence level while more than half of the participants $(51 \%)$ agreed that orthodontic treatment improved their ability to communicate effectively. [Figure $7 \& 8$ ]

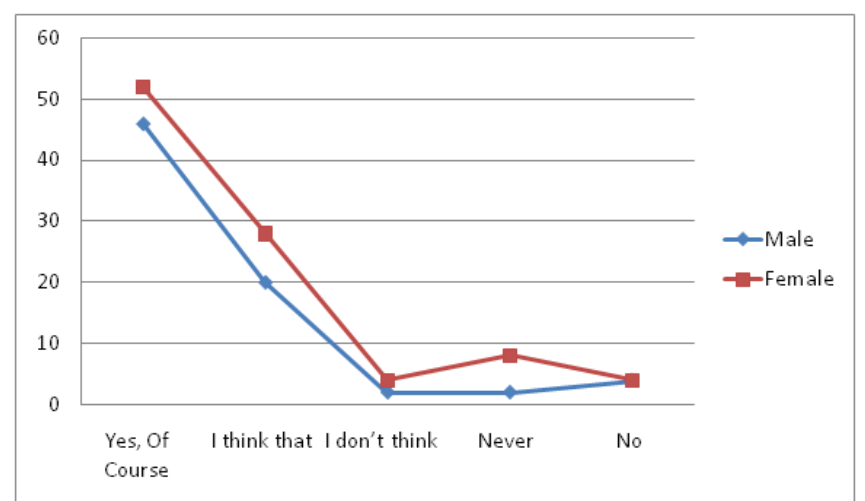

Figure 7: Did orthodontic correction improve your selfconfidence level?

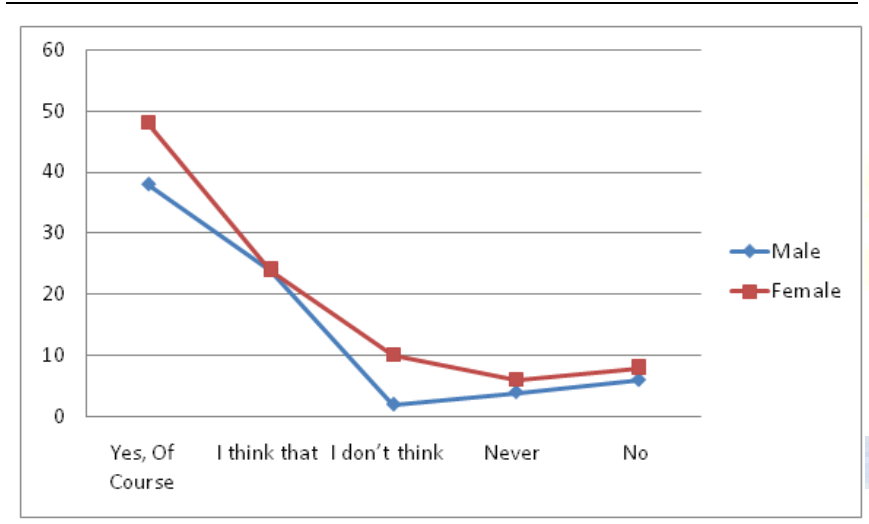

Figure 8: Did orthodontic correction improve your communication skills?

Duration of orthodontic treatment was the most difficult thing that the patients experienced followed by other factors at a non significant level. [Figure 9].

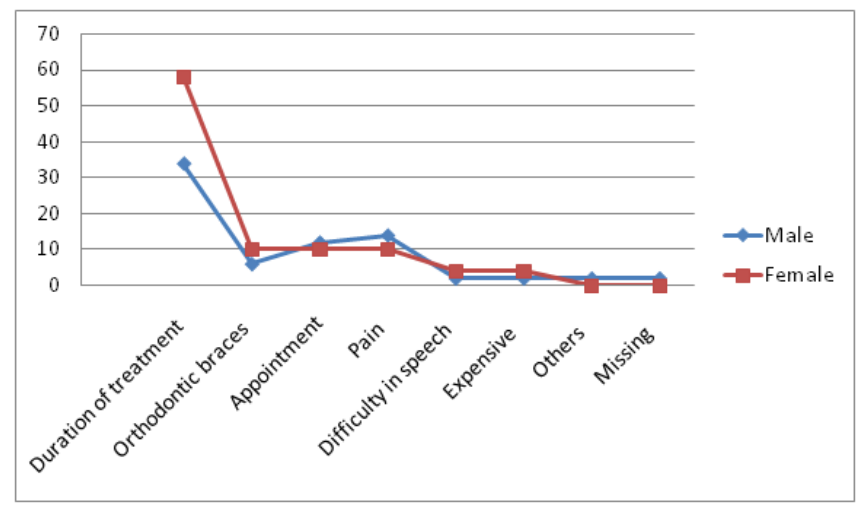

Figure 9: What is the most difficult thing during your orthodontic treatment?

\section{Discussion}

In general, high levels of satisfaction with their teeth following an orthodontic treatment have been reported in many other studies. ${ }^{[13,14]}$ The present study found out that $58 \%$ of the participants were very satisfied and $40 \%$ were satisfied with the overall result after the treatment. Al-Omiri and Alhaija reported that $34 \%$ of subjects were totally satisfed whereas Larsson and Bergsrom reported that the satisfaction rate was $74 \%{ }^{[13,15]}$ Birkeland et al. reported a high degree of satisfaction with orthodontic treatment results $(95.4 \%) .{ }^{[16]} \mathrm{Al}$-Omiri and Alhaija's study found that only $4 \%$ of patients treated with orthodontic were dissatisfied with their teeth after treatment, ${ }^{[13]}$ and the present study found that only 5 of the patients were dissatisfied with their overall treatment results. Hence, it should be noted that the rates of dissatisfaction are fairly similar, despite differences in treatment location. Looking at gender differences, some studies reported that gender is not a major factor in dental satisfaction. ${ }^{[13,15,17]}$

Others show that females tend to be more concerned about their appearance and thus find a greater need for this treatment as compared to males. ${ }^{[18,19]}$ Moreover, Phillips et al found that the expectations of orthodontic treatment among males differed from those among females. ${ }^{[20]}$ The present study found that the "gender factor" to be different only in the level of satisfaction in regard to smile appearance after treatment while the other factor has shown almost the same result as it has no significant effect. One study in British and American community found that from a patient's perspective, the most important reason in deciding to have an orthodontic treatment was to improve their appearance. ${ }^{[21]}$ Similarly, $95 \%$ of the subjects in the present study stated that their main concern was improving their aesthetic appearance. The literature shows that most individuals who have undergone orthodontic treatment feel that they have benefited from the treatment; even if dramatic changes in facial appearance are not always evident. ${ }^{[22]}$

The present study found that a high proportion of patients were satisfied with their final overall profiles. Moreover, improved patient self-confidence together with a more aesthetic facial appearance accounted for the highest level of patient satisfaction.

Bos et al. found that patients who had undergone orthodontic treatment had a more positive view of the treatment than those who did not. ${ }^{[18]}$

In recent years, there has been growing acceptance among dental professionals that aesthetics and their psycho-social impacts are an important beneft from the treatment. ${ }^{[25,26]}$ Some patients reported significant improvement in their self-confidence related to their appearance after orthodontic treatment. ${ }^{[14,27]}$ In the present study, a high percentage $(86 \%)$ of the subjects stated that orthodontic treatment had a positive influence on their self-confidence levels. AlOmiri and Alhaija pointed out the importance of psychological assess-ments of patients undergoing orthodontic treatment and suggested that satisfaction levels could be correlated with personality traits. ${ }^{[13,28]}$

\section{Conclusion}

Responses to the questionnaire revealed that, in general, patients who undergo orthodontic treatment remained 
satisfied with their facial aesthetics in the long-term following orthodontic treatment. In addition, there was no evidence of differences in satisfaction ratings between the two genders, male and female. Therefore, orthodontic treatment has a clear impact in helping improve the psychosocial status of the patient as majority of them reported high improvement in their self-confidence and communication skills.

\section{References}

1. Birkeland K, Katle A, Løvgreen S, Bøe O E, Wisth P J. A longitudinal study among 11- and 15-year-olds and their parents on factors influencing the decision about orthodontic treatment. Journal of Orofacial Orthopedics 1999;60:292-307.

2. Gosney M B E. An investigation into some of the factors influencing the desire for Orthodontic Treatment. British Journal of Orthodontics 1986;13:87-94.

3. Jenny J. A social perspective on need and demand for orthodontic treatment. International Dental Journal 1975;25:248-256.

4. Baldwin D C. Appearance and aesthetics in oral health. Community Dentistry and Oral Epidemiology 1980; 8:244-256.

5. Korabik K. Self-concept changes during orthodontic treatment. Journal of Applied Social Psychology. 1994; 24:1022-1034.

6. Bondemark, et al. Long term Stability of Orthodontic Treatment and Patient Satisfaction. Angle Orthodontist, 2007;77.

7. Theunissen NC, et al, The proxy problem: child versus parent report in HRQOL research. Qual Life Res. 1998;7:387-397.

8. Jenkinson C, et al. T. Patients' experiences and satisfaction with health care: results of a questionnaire study of specific aspects of care. Qual Safe Health Care. 2000; 11:335-339.

9. Kravitz RL. Patients' expectations for medical care: an expanded formulation based on review of the literature. MedCare Res Rev. 1996; 53:3-27.

10. Thompson AG, Sunol R. Expectations as determinants of patient satisfaction: concepts, theory and Evidence. Int JQual Health Care. 1995;7:127-141.

11. Burke L, Croucher R. Criteria of good dental practice generated by general dental practitioners and Patients. Int DentJ. 1996;46:3-9.

12. Annalise McNair; et al. Piloting a Patient based Questionnaire to
Assess Patient Satisfaction with the Process of Orthodontic Treatment, Angle Orthodontist, 2009;79.

13. Al-Omiri MK, Abu Alhaija ES. Factors affecting patient satisfaction after orthodontic treatment. Angle Orthod 2006;76:422-431.

14. Birkeland K, Boe OE, Wisth PJ. Subjective assessment of dental and psychosocial effects of orthodontic treatment. J Orofac Orthop 1997;58:44-61.

15. Larsson BW, Bergsröm K. Adolescents' perception of the quality of orthodontic treatment. Scand J Caring Sci 2005;19:95-101.

16. Birkeland K, Bøe OE, Wisth PJ. Relationship between occlusion and satisfaction with dental appearance in orthodontically treated and untreated groups. A longitudinal study. Eur J Orthod 2000;22,509-518.

17. Bos A, Hoogstraten J, Prahl-Andersen B. Expectations of treatment and satisfaction with dentofacial appearance in orthodontic patients. AmJ Orthod Dentofacial Orthop 2003;123:127-132.

18. Shaw WC. Factors influencing the desire fororthodontic treatment. Eur J Orthod 1981;3:151-162.

19. Wheeler TT, McGorray SP, Yurkiewicz L, Keeling SD, King GJ. Orthodontic treatment demandand need in third and fourth grade school children.Am J Orthod Dentofacial Orthop 1994;106:22-23.

20. Phillips C, Broder HL, Bennett ME. Dentofacial disharmony, motivations for Seeking treatment. Int J Adult Orthodon Orthognath Surg 1997;12:7-15.

21. Tulloch JF, Shaw WC, Underhill C, Smith A, JonesG, Jones M. A comparison of attitudes toward orthodontic treatment in British and American communities. Am J Orthod 1984;85,253-259.

22. Ostler S, Kiyak HA. Treatment expectations versus outcomes among orthognathic surgery patients. Int J Adult Orthodon Orthognath Surg 1991;6:247-255.

23. Arat ZM, Akcam MO, Gokalp H. Long-term effects of chin- cap therapy on the temporomandibularjoints. Eur J Orthod 2003;25:471475.

24. Zhou YH, Hägg U, Rabie ABM. Patient satisfaction following orthognathic surgical correction of skeletal Class III malocclusion. Int JAdult Orthodon Orthognath Surg 2001;16:99-107.

25. Giddon DB. Orthodontic applications of psychological and perceptual studies of facial aesthetics. Semin Orthod 1995;1:82-93.

26. Hunt O, Hepper P, Johnston C, Stevenson M, Burden D. Professional perceptions of the benefts of orthodontic treatment. Eur J Orthod 2001;23,315-323.

27. Albino Jen, Lawrence SD, Tedesco LA. Psychological and social effects of orthodontic treatment. J Behav Med 1994;17:81-98.

Copyright: (C) the author(s), 2019. It is an open-access article distributed under the terms of the Creative Commons Attribution License (CC BY 4.0), which permits authors to retain ownership of the copyright for their content, and allow anyone to download, reuse, reprint, modify, distribute and/or copy the content as long as the original authors and source are cited.

How to cite this article: Platia S, Kumar M, Khanna A, Kumari S. Evaluation of Post Treatment Satisfaction in Orthodontic Patients. Asian J. Med. Res. 2019;8(1):DE04-DE07.

DOI: dx.doi.org/10.21276/ajmr.2019.8.1.DE2 